\title{
A Parameterisation for the Threshold Shear Velocity to Initiate Deflation of Dry and Wet Sediment
}

\author{
Wim M. Cornelis", Donald Gabriels and Roger Hartmann \\ Dep. Soil Management and Soil Care, International Centre for Eremology, \\ Ghent University, Coupure links 653, B-9000 Gent, Belgium
}

\begin{abstract}
A new parameterisation for the threshold shear velocity to initiate deflation of dry and wet particles is presented. It is based on the balance of moments acting on particles at the instant of particle motion. The model hence includes a term for the aerodynamic forces, including the drag force, the lift force and the aerodynamic moment force, and a term for the interparticle forces. The effect of gravitation is incorporated in both terms. Rather than using an implicit function for the effect of the aerodynamic forces as reported earlier in literature, a constant aerodynamic coefficient was introduced. From consideration of the van der Waals force between two particles, it was further shown that the effect of the interparticle cohesion force between two dry particles on the deflation threshold should be inversely proportional to the particle diameter squared. The interparticle force was further extended to include wet bonding forces. The latter were considered as the sum of capillary forces and adhesive forces. A model that expresses the capillary force as a function of particle diameter squared and the inverse of capillary potential was deduced from consideration of the well-known model of Fisher and the Young-Laplace equation. The adhesive force was assumed to be equal to tensile strength, and a function which is proportional to particle diameter squared and the inverse of the potential due to adhesive forces was derived. By combining the capillary force model and the adhesive force model, the interparticle force due to wet bonding was simplified and written as a function of particle diameter squared and the inverse of matric potential. The latter was loglinearly related to the gravimetric moisture content, a relationship that is valid in the low-moisture content range that is important in the light of deflation of sediment by wind. By introducing a correction to force the relationship to converge to zero moisture content at oven dryness, the matric potential-moisture content relationship contained only one unknown model parameter, viz. moisture content at $-1.5 \mathrm{MPa}$. Working out the model led to a rather simple parameterisation containing only three coefficients. Two parameters were incorporated in the term that applies to dry sediment and were determined by using experimental data as reported by Iversen and White [1982. Sedimentology 29, 111-119]. The third parameter for the wet-sediment part of the model was determined from wind-tunnel experiments on prewetted sand and sandy loam aggregates. The model was validated using data from wind-tunnel experiments on the same but dry sediment, and on data obtained from simulations with the model of Chepil [1956. Soil Sci. Soc. Am. Proc. 20, 288-292]. The experiments showed that soil aggregates should be treated as individual particles with a density equal to their bulk density. Furthermore, it was shown that the surface had to dry to a moisture content of about $75 \%$ of the moisture content at $-1.5 \mathrm{MPa}$ before deflation became sustained. The threshold shear velocities simulated with our model were found to be in good agreement with own observations and with simulations using Chepil's model.
\end{abstract}

Keywords: wind erosion, sediment transport, moisture, particles, soils, sand

E-mail address: wim.cornelis@UGent.be

\section{Introduction}

A crucial parameter in predicting wind erosion is the threshold shear velocity. This is the minimal shear velocity required to initiate deflation of soil particles. Amongst the several factors that govern threshold conditions on Earth, particle size, particle density and near-surface moisture are the most significant, given that the fluid density is more or less constant.

The influence of particle size and particle density is well documented in the work of Greeley, Iversen,
Pollack and White (see e.g. Iversen et al., 1976a, 1976b; Iversen and White, 1982; Greeley and Iversen, 1985). They developed implicit functions to predict the threshold shear velocity of dry particles that can only be solved iteratively, disregarding the true nature of interparticle forces. These functions are widely used in wind-erosion models such as WEAM (Shao et al., 1996).

The near-surface moisture content strongly contributes, through adhesion and capillary effects, to 
the binding forces keeping particles together (McKenna-Neuman and Nickling, 1989). Albeit the several studies that were conducted to determine the influence of moisture on entrainment of soil or sand particles by wind, its effect is still not well understood (Namikas and Sherman, 1995; Shao, 2000; Cornelis and Gabriels, 2003a).

In this paper a new parameterisation for the threshold shear velocity to initiate deflation of dry and wet particles is presented. It is based on the balance of moments acting on particles at the instant of particle motion. The theory of Stout and Zobeck (1996, 1997), which takes into account wind-velocity fluctuations to determine (dry) deflation thresholds in the field, is not considered. Working out the model led to a rather simple parameteris ation containing only three coefficients. Two parameters were incorporated in the term that applies to dry sediment and were determined by using experimental data as reported by Iversen and White (1982). The third parameter for the wet-sediment part of the model was determined from wind-tunnel experiments on prewetted sand and sandy loam aggregates. The model was validated using data from wind-tunnel experiments on the same but dry sediment, and on data obtained from simulations with the model of Chepil (1956). Crust formation, occurring at the soil surface as it dries out under the influence of the wind, was avoided.

\section{Model development}

A particle resting on a surface bed and exposed to a fluid stream experiences several forces: a drag force $F_{D}$, a lift force $F_{L}$, an aerodynamic-moment force $F_{M}$, the gravity force $F_{G}$ and an interparticle force $F_{I p}$ (Iversen et al., 1976b).

The aerodynamic forces (in N) can be written as (Iversen et al., 1976b):

$$
\begin{aligned}
& F_{D}=K_{F} \rho_{f} u_{*_{t}}^{2} d^{2}, \\
& F_{M}=K_{M} \rho_{f} u_{*_{t}}^{2} d^{2}, \\
& F_{L}=K_{L} \rho_{f} u_{*_{t}}^{2} d^{2},
\end{aligned}
$$

where $\rho_{f}$ is the fluid density $\left(\mathrm{kg} \mathrm{m}^{-3}\right), u_{* t}$ is the threshold shear velocity $\left(\mathrm{m} \mathrm{s}^{-1}\right), d$ is the particle diameter (m), and $K_{F}, K_{M}$ and $K_{L}$ are dimensionless proportionality constants. These coefficients are in theory functions of the threshold Reynolds number $R e_{t}=\frac{u_{*_{t}} d}{\mathrm{v}}$, where $\mathrm{v}$ is the kinematic viscosity $\left(\mathrm{m}^{2}\right.$ $\left.\mathrm{s}^{-1}\right)$.
The gravitational force $F_{G}(\mathrm{~N})$ on a particle submerged in a fluid can be represented by (Cornelis et al., 2003a):

$$
F_{G}=(1+w) K_{G}\left(\rho_{s}-\rho_{f}\right) g d^{3},
$$

where $w$ is the gravitational moisture content $(\mathrm{kg}$ $\left.\mathrm{kg}^{-1}\right), \rho_{s}$ is the particle density $\left(\mathrm{kg} \mathrm{m}^{-3}\right), g$ is the gravitational acceleration $\left(\mathrm{m} \mathrm{s}^{-2}\right)$, and $K_{G}$ is a dimensionless proportionality constant $(=\pi / 6$ for ideally spherical, smooth particles).

The interparticle force is caused by cohesion between individual particles. In the two phase solidair state it results from electrostatic-force bonding and van der Waals -force bonding (Harnby, 1992). The electrostatic force $F_{I p, e}(\mathrm{~N})$ (or Coulomb force) occurs when two solids in rubbing contact charge each other electrostatically. However, the electrostatic forces are several degrees of magnitude smaller than the van der Waals forces (Hamby, 1992) and can therefore be omitted here.

The van der Waals force $F_{I p, v d W}(\mathrm{~N})$ (or London dispersion force) is responsible for the attraction of molecules without permanent dipoles. The van der Waals force of attraction between a sphere and a flat surface can be expressed as (Adamson and Gast, 1997):

$$
F_{I p, v d W_{\text {plate-sphere }}}=\frac{A_{H}}{12 x_{d}^{2}} d,
$$

where $A_{H}$ is the Hamaker constant $(\mathrm{J})$, named after its developer (Hamaker, 1937), and $x_{d}$ is the distance between the particle and the plate $(\mathrm{m})$. In the case of two spheres, the force is twice as low. Since soil particles are mainly a mixture of spheres and plates, it can be assumed that $F_{I p}$ is proportional to $d$. When considering $A_{H}$ and $x_{d}$ as being constant, Eq. (5) can be simplified as (Cornelis and Gabriels, 2003b):

$$
F_{\text {Ip, vdW }}=K_{v d W} d \text {, }
$$

where $K_{v d W}$ is a proportionality coefficient $\left(\mathrm{N} \mathrm{m}^{-1}\right)$. However, it is rather doubtful that $x_{d}$ is a constant for all particle size ranges, as it will not only depend on particle geometry, but also on the degree of compaction.

The bonding forces between two particles in the three-phase state solid-air-liquid, i.e. in the case of wet sediment, are due to liquid-bridge bonding (capillary forces) and adsorbed-layer bonding (adhesion forces). The liquid bridges exert an attractive force between particles once they are formed (Harnby, 1992). When considering the model of Fisher (1926) and the well-known Young-Laplace equation, the capillary force $F_{I p, c}(\mathrm{~N})$ can be written as (Cornelis et al., 2003a): 


$$
F_{I p, c}=\frac{G_{c} \sigma^{2}}{\left|\psi_{c}\right|} d^{2},
$$

where $G_{c}$ is a parameter accounting for soil and fluid properties $\left(\mathrm{m}^{-2}\right), \sigma$ is the surface tension of the liquid $\left(\mathrm{N} \mathrm{m}^{-1}\right)$, and $\psi_{c}$ is the capillary potential, which is the negative of suction (MPa). The finally obtained Eq. (7) differs from the capillary-force model as deduced by McKenna-Neuman and Nickling (1989) in that for a given surface tension and capillary potential, the capillary force increases with the square of particle diameter. Furthermore, the geometric parameter $G_{c}$ is not merely related to the particle angle as in the case of the McKenna-Neuman and Nickling model (1989). It is on the contrary a complex function that can only be determined through curve fitting and hence the model does not pretend to be soluble if particle angle is known.

The adsorbed-layer bonding is caused by the overlapping of the adsorbed layers of neighbouring particles. Its strength is proportional to the tensile strength of the adsorbed film and the area of contact. Notwithstanding the fact that the forces due to adsorbed-layer bonding are often considered as negligible for soil particles (Namikas and Sherman, 1995), and since the contribution of alsorbed-layer bonding to the attraction between two particles increases with moisture content as the contact area increases, the force associated with adsorbed-layer bonding $F_{I p, a}(\mathrm{~N})$ is assumed here to be equal to the tensile strength. As moisture content increases, the width of the waist of the water wedge between the particles increases. We can therefore assume $F_{I p, a}$ to be inversely proportional to the suction in the adsorption films. Since $F_{I p, a}$ depends on the contact area between the water films, it is proportional to the square of particle diameter as well. When using dimensional analysis, the force due to adsorbed-layer bonding can be written as (Cornelis et al., 2003a):

$$
F_{I p, a}=\frac{G_{a} \sigma^{2}}{\left|\psi_{a}\right|} d^{2},
$$

where $G_{a}$ is a proportionality factor accounting for soil and fluid properties $\left(\mathrm{m}^{-2}\right)$, and $\psi_{a}$ is the potential in the adsorbed layers (MPa).

The interparticle force due to 'wet' bonding $F_{I p, a c}$ (N) can finally be written as (Cornelis et al., 2003a):

$$
F_{I p, a c}=\frac{G \sigma^{2}}{\left|\psi_{m}\right|} d^{2},
$$

where $G$ is a proportionality factor accounting for soil and fluid properties $\left(\mathrm{m}^{-2}\right)$, and $\psi_{m}$ is the matric potential (MPa). Although this is a simplified representation of the interparticle force, it is believed that it is a hypothesis that is sufficiently appropriate in the light of prediction of deflation of soil particles. The reason for combining Eq. (7) and (8) rather than considering the capillary force and adsorption force separately, was to disregard the minimum soil moisture used by Fécan et al. (1999), below which the equilibrium between capillary and adsorbed water is shifted towards the latter. Further investigation is needed to model this minimum soil moisture. Note that the upper limit of $F_{I p, a c}$ to play a role in keeping particles together is at the point where the individual water wedges at the contact points begin to coalescence as water content becomes sufficiently high. The lower limit of course is at oven dryness. The total interparticle force $F_{I p}$ is the sum of $F_{I p, v d W}$ (Eq. (6)) and $F_{I p, a c}$ (Eq. (9)).

Although it is the matric potential $\psi_{m}$ that will determine the magnitude of the interparticle force between particles of wet sediment, requirement of matric potential data forms a key limitation from a practical perspective (Namikas and Sherman, 1995). However, a moisture retention curve relates the matric potential to moisture content, a parameter that can be determined with much higher precision at the soil surface and at low moisture contents. For low matric potentials, Rossi and Nimmo (1994) used a linear relationship between the logarithm of matric potential and moisture content. Inspection of data sets from Campbell and Shiozawa (1992) and Schofield (1935), who measured moisture contents of soils ranging from sand to silty clay at matric potentials far beyond $\psi_{m}=-1.5 \mathrm{MPa}$, indicate a linear relationship between the logarithm of matric potential and the moisture content, for matric potentials between its value at oven dryness $\left(105^{\circ} \mathrm{C}\right)$, i.e. ca. $-10^{3} \mathrm{MPa}$, and $\psi_{m} \approx-0.03 \mathrm{MPa}$ (for sand) to $\psi_{m} \approx-1 \mathrm{MPa}$ (for silt loam). Since, for the given soils, these matric potentials correspond to volumetric moisture contents ranging from respectively ca. $0.05 \mathrm{~m}^{3} \mathrm{~m}^{-3}$ to ca. 0.15 $\mathrm{m}^{3} \mathrm{~m}^{-3}$, it is plausible to represent that matric potential that determines the effect of moisture on the threshold shear velocity, by an exponential equation (Cornelis et al., 2003a):

$\psi_{m}=\psi_{m d} \mathrm{e}^{-6.5 \frac{w}{w_{1.5}}}$

where $\psi_{m d}$ is the matric potential at oven dryness $\approx$ $\left.-10^{3} \mathrm{MPa}\right)$, and $w_{1.5}$ is the gravimetric moisture content at $-1.5 \mathrm{MPa}\left(\mathrm{kg} \mathrm{kg}^{-1}\right)$. Note that the coefficient 6.5 is equal to $\ln \left(10^{3} \mathrm{MPa} / 1.5 \mathrm{MPa}\right)$.

At the instant of particle motion, the destabilising forces $F_{D}, F_{L}$ and $F_{M}$ will exceed the stabilising forces $F_{G}$ and $F_{I p}$, and the particle will 
pivot about a downstream point of contact. At the instant of deflation the moments are balanced:

$$
F_{D} a^{\prime}+F_{M} d=\left(F_{G}-F_{L}\right) b^{\prime}+F_{I p} c^{\prime},
$$

where $a^{\prime}, b^{\prime}$ and $c^{\prime}$ are moment arm lengths (m) (and $d$ is particle diameter). When substituting Eqs. (1) to (4), Eq. (6), and Eq. (9) into Eq. (11) and with $a^{\prime}=$ $a_{1} d, b^{\prime}=b_{1} d$ and $c^{\prime}=c_{1} d$, the threshold shear velocity $u_{*_{t}}$ becomes:

$$
\begin{aligned}
& u_{*_{t}}=\sqrt{\frac{b_{l} K_{G}}{a_{1} K_{D}+b_{l} K_{L}+K_{M}}} \times \\
& \sqrt{1+w+\frac{c_{l} K_{v d W}}{b_{l} K_{G}\left(\rho_{s}-\rho_{f}\right) g d^{2}}\left(1+\frac{G \sigma^{2} d}{K_{v d W}\left|\psi_{m}\right|}\right)} \times \\
& \sqrt{\frac{\rho_{s}-\rho_{f}}{\rho_{f}} g d},
\end{aligned}
$$

or

$u_{* t}=\sqrt{A_{1}} \times$

$$
\begin{aligned}
& \sqrt{\left[\left[1+w+A_{2} \frac{1}{\left(\rho_{s}-\rho_{f}\right) g d^{2}}\left(1+A_{3} \frac{\sigma^{2} d}{\left.\left.\mid \psi_{m d} \mathrm{e}^{-6.5 \frac{w}{w_{l .5}}}\right)\right]} \times\right.\right.\right.} \\
& \sqrt{\frac{\rho_{s}-\rho_{f}}{\rho_{f}} g d},
\end{aligned}
$$

where $A_{1}, A_{2}$ and $A_{3}$ are model parameters (resp. dimensionless, in $\mathrm{N} \mathrm{m}^{-1}$ and in $\mathrm{N}^{1} \mathrm{~m}^{-1}$ ). For more details about the model development, the reader is referred to Cornelis and Gabriels (2003b), and Cornelis et al. (2003a).

\section{Materials and Methods}

The values for the parameters $A_{1}$ and $A_{2}$ were determined from non-linear least-squares analysis at the wind-tunnel data reported by Iversen and White (1982), and validated on data from our own windtunnel experiments on six fractions of dry dune sand and silt loam aggregates. The particle-size ranges that were used included 100-200 $\mu \mathrm{m}, 200-500 \mu \mathrm{m}$, and 50-500 $\mu \mathrm{m}$ for the dune sand and 50-100 $\mu \mathrm{m}, 100-$ $200 \mu \mathrm{m}, 200-300 \mu \mathrm{m}$, and 300-500 $\mu \mathrm{m}$ for the soil aggregates. The aggregates were taken from a sandy loam soil on an agricultural field near Melle (Belgium), whereas the sand was collected from the Belgian coastal dunes (Bredene). The particle density was considered to be $2.65 \mathrm{Mg} \mathrm{m}^{-3}$ for the dune sand and $1.47 \mathrm{Mg} \mathrm{m}^{-3}$ for the silt loam aggregates. Note that the latter value corresponds to the bulk density of the aggregates. The value for the parameter $A_{3}$ was derived from least-squares analysis on data from wind-tunnel experiments with the same but prewetted sediment. The final model was validated against simulations with the model of Chepil (1956). Although this model is rather controversial (Gregory and Darwish, 1990; Namikas and Sherman, 1995; Fécan et al., 1999), it was chosen because of its good performance in predicting the threshold shear velocity as a function of the moisture content of the uppermost surface layer (Cornelis and Gabriels, 2003a).

Our own experiments were conducted in the closed-circuit blowing-type wind tunnel of the International Centre for Eremology, Ghent University, Belgium (Gabriels et al., 1997). The test section of the wind tunnel was $12 \mathrm{~m}$ long, $1.2 \mathrm{~m}$ wide and $2.5 \mathrm{~m}$ high, and the boundary layer was set at a height of about $0.60 \mathrm{~m}$, by using a combination of spires and roughness elements (Cornelis, 2002).

A sample tray $0.95 \mathrm{~m}$ long, $0.40 \mathrm{~m}$ wide and $0.02 \mathrm{~m}$ deep was located at a distance of $6.0 \mathrm{~m}$ downwind from the entrance of the wind-tunnel test section. The tray was filled with air-dried or prewetted sediment. The sample trays were then exposed to wind with different shear velocities and were subjected to evaporation in the case of the wet sediment.

A saltiphone, which is an acoustic sediment sensor that measures the number of saltating particles that bounce against a microphone (Spaan and van den Abeele, 1991), was continuously monitoring any particle deflating from the sample tray. It can hence be used to determine the instant of particle motion. The impact energy of the soil aggregates smaller then $200 \mu \mathrm{m}$ was, however, too low to be recorded by the saltiphone. In those cases, particle entrainment was therefore determined visually using a Neon-Helium laser beam (Logie, 1982). The detailed procedures to determine the deflation threshold for dry sediment and for wet sediment are both described in Cornelis (2002).

Moisture content was determined gravimetrically on three small samples taken down to $1 \mathrm{~mm}$ from the instant of continuous particle entrainment, i.e. from the moment that three impacts were recorded on the saltiphone within one minute. Since we could visually observe differences in moisture content over the tray, two samples were taken at a 'drier' section and one sample at a 'wetter' section of the sample tray. Continuous deflation only occurred once the first 'drier' sections appeared. The moisture content at $-1.5 \mathrm{MPa} w_{1.5}$ was determined using a pressure 
chamber (Soilmoisture Equiment ${ }^{1}$, Santa Barbara CA, USA). The relative humidity, evaporation rate and temperature were constant within each test run.

The wind velocity was measured at a $1-\mathrm{Hz}$ frequency with $16-\mathrm{mm}$ vane probes (Testo, Lenzkirch, Germany) mounted at five different heights, and was used to compute the shear velocity using the well-known Prandt-von Kármán logarithmic law.

\section{Results and Discussion}

The values for the parameters $A_{1}$ and $A_{2}$ determined from least-squares analysis at the Iversen and White data (1982) were 0.013 and $1.710^{-4} \mathrm{~N} \mathrm{~m}^{-1}$ respectively. In Fig. 1, the Iversen and White data are plotted as well as the data predicted by the proposed (calibrated) model for dry sediment (model CGH) and the model of Iversen and White (1982) (model IW). Both models seem to show a similar performance and $R^{2}$ was resp. 0.997 and 0.992 , when omitting the extremely high particle density data from the Iversen and White data set $\left(8.9 \mathrm{Mg} \mathrm{m}^{-3}\right.$ and 11.4 $\mathrm{Mg} \mathrm{m}^{-3}$ ).

In Fig. 2, the presented model is validated against our own wind-tunnel data. It is shown that the threshold shear velocities predicted by the proposed model agree very well with the observed data. $R^{2}$ was 0.995 and 0.972 for dune sand grains and silt loam aggregates respectively. This illustrates that it is acceptable to replace the implicit function for the aerodynamic term in the Iversen and White model (1982) with a constant and that soil aggregates can be treated as individual particles with a density equal to their bulk density. Prediction of mass transport for a given soil should therefore be based on minimallydispersed particle-size distributions, rather then fullydispersed ones, as was also suggested by Shao (2000).

The third model parameter $A_{3}$ was determined from least-squares analysis at data from wind-tunnel experiments on prewetted sediment. In Fig. 3, the observed $u_{*}$ values are plotted as a function of $w$. Also plotted is the proposed model with $A_{3}=310^{14}$ $\mathrm{N}^{-1} \mathrm{~m}^{-1}$. Although the data show a lot of scatter and the $R^{2}$ determined from regression with the 'drier'section data - deflation only occurred from the drier areas of the sample tray - was in all cases lower then

\footnotetext{
${ }^{1}$ Mention of company names is for the convenience of the reader and does not constitute any endorsement in whatever sense from the authors.
}

0.75 , it can be seen that the model follows the 'drier'section data rather well. At low moisture contents, the increase in $u_{* t}$ with $w$ is very gradual, until at a given moisture content, a steep increase in $u_{*}$ becomes apparent. The threshold shear velocity soon reaches a very high value and a critical moisture content, above which there is no wind erosion, can be observed. This is in line with observations of Chepil (1956), Bisal and Hsieh (1966) and Saleh and Fryrear (1995). Therefore, there is no need to quantify the upper boundary conditions of our parameterisation.

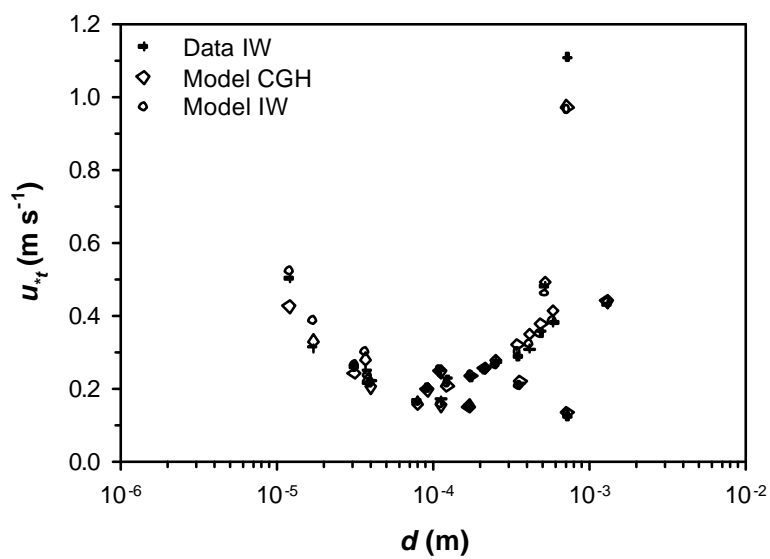

Fig. 1. The threshold shear velocity of dry sediment $u_{*_{t}}$ vs. particle diameter $d$ for different particle densities: Iversen and White (1982) data, and data from simulations with the model presented in this study (model CGH) and with the Iversen and White (1982) model (model IW)

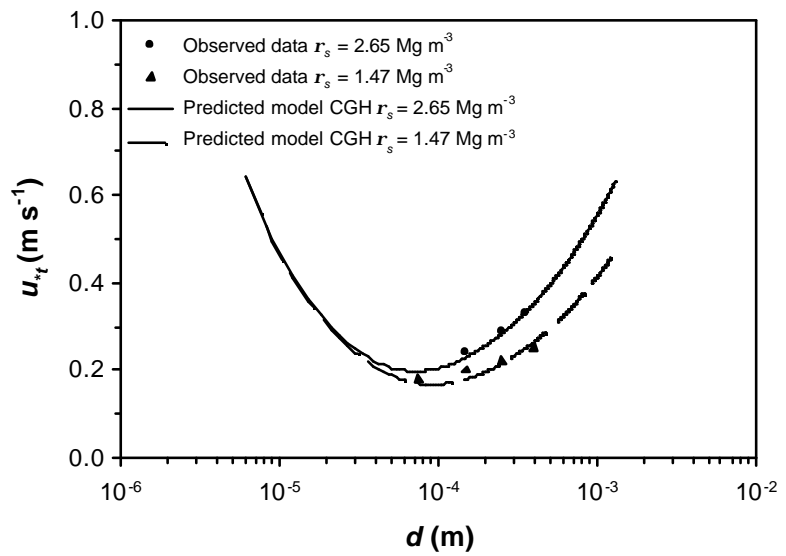

Fig. 2. The threshold shear velocity of dry sediment $u_{*_{t}}$ vs. particle diameter $d$ for two different particle densities $\rho_{s}$ : observed data (our own wind-tunnel experiments), and predictions with the model presented in this study (model CGH) 

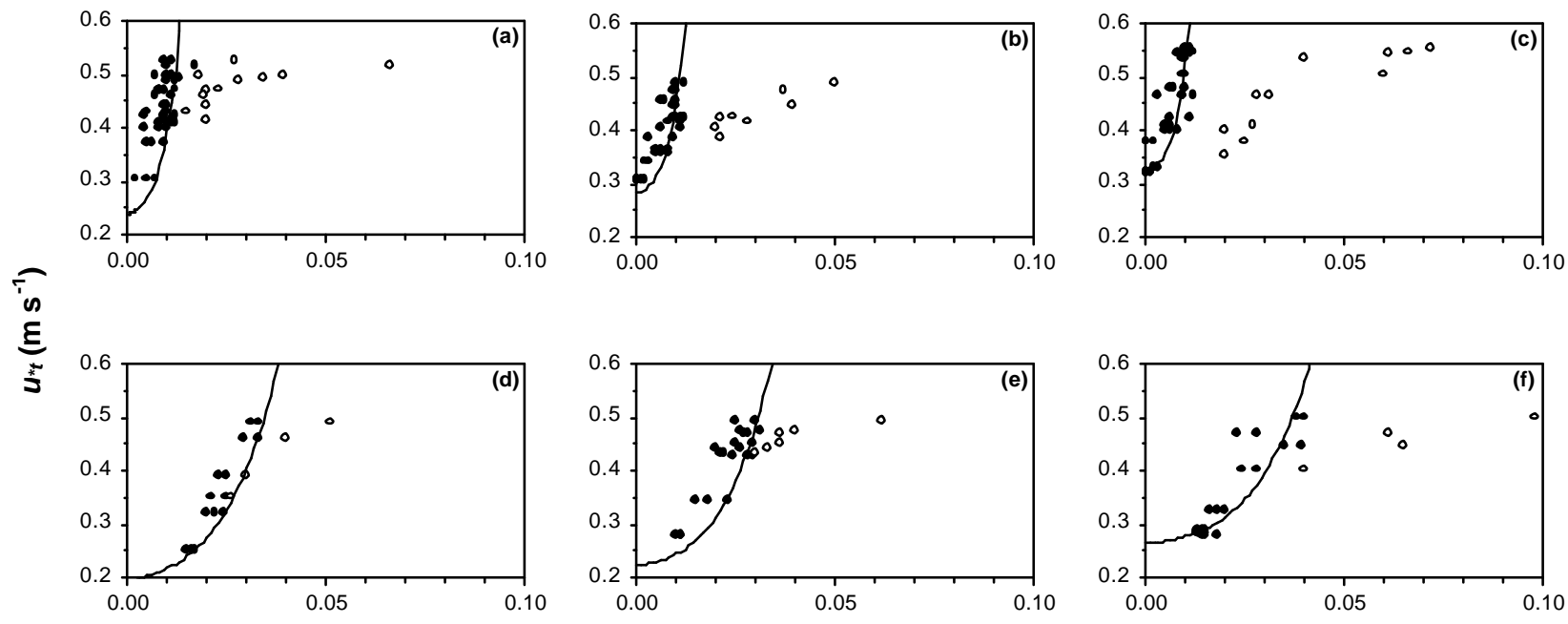

$w\left(\mathrm{~kg} \mathrm{~kg}^{-1}\right)$

- observed ('drier' section) o observed ('wetter' section) - model CGH

Fig. 3. Threshold shear velocity $u_{*_{t}}$ of wet sediment vs. gravimetric moisture content $w$ : observed data for dune sand with particle-size range of 100-200 $\mu \mathrm{m}$ (a), 50-500 $\mu \mathrm{m}$ (b), 200-500 $\mu \mathrm{m}$ (c), and sand loam soil aggregates with particle-size range of $100-200 \mu \mathrm{m}$ (d), $200-300 \mu \mathrm{m}$ (e) and 300-500 $\mu \mathrm{m}$ (f). Also plotted is the model proposed in this study (model CGH) with $A_{3}=310^{14} \mathrm{~N}^{-1} \mathrm{~m}^{-1}$.

As a validation, in Fig. 4, the threshold shear velocities $u_{*}$ predicted by the model of Chepil (1956) (model $\mathrm{C}$ ) are plotted against the threshold shear velocities $u_{*}$ predicted by the model presented in this study (model CGH). Figure 4 clearly illustrates that both models agree very well for threshold shear velocities not exceeding $0.5 \mathrm{~m} \mathrm{~s}^{-1}$, which was about the maximum shear velocity generated in Chepil's study. This value corresponds with a $w / w_{1.5}$ ratio of 0.75 and is close to the critical moisture content above which no wind erosion will take place. This means that the soil surface has to dry to a rather low value before deflation will occur. However, this is only true under rainless conditions. Experiments on beaches during rainfall (de Lima et al., 1992; van Dijk et al., 1996; Sherman et al., 1998) and in a wind tunnel with rainfall simulator facility (Erpul et al., 2002, 2003; Cornelis et al., 2003b, 2003c) showed that, during rain events, substantial sediment transport can occur at near-surface moisture contents far above the critical moisture content of $0.75 w_{1.5}$ which is valid for rainless conditions.

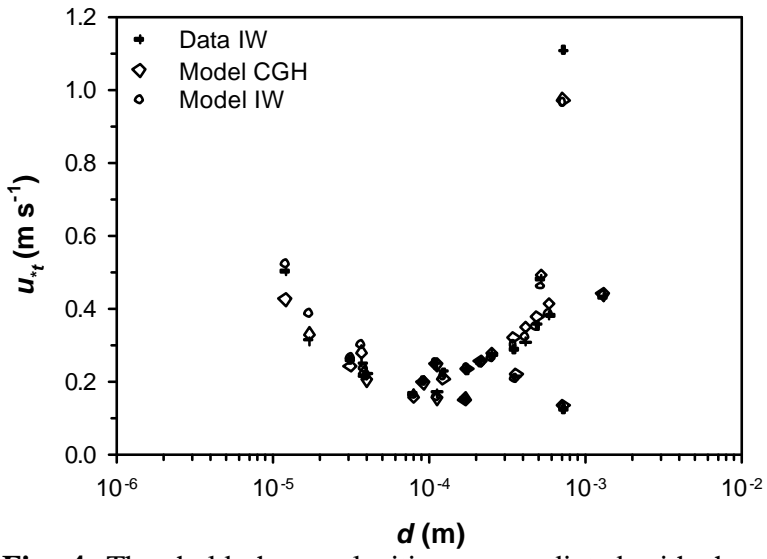

Fig. 4. Threshold shear velocities $u_{* t}$ predicted with the model of Chepil (1956) (model C) vs. threshold shear velocities $u_{*_{t}}$ predicted with the model presented in this study (model CGH)

An important observation in our study was that deflation only occurred on the drier spots of the sample tray. This indicates that wind erosion can take place, even if the average surface moisture content is relatively high. However, as deflation is limited to drier spots, the total mass transport rate will accordingly be rather low. These observations could also explain why e.g. Sarre (1988) reported sand 
transport on beaches even if moisture content was $0.14 \mathrm{~kg} \mathrm{~kg}^{-1}$. The existence of a high spatial variability in surface moisture content, even on bare dune sand which at first sight show the greatest homogeneity, was observed by Ritsema and Dekker (1994). To illustrate the occurrence of 'wetter' and 'drier' spots and their possible effect on the moisture content measurements, the $w$ values of the 'wetter' spots are plotted in Fig. 3 as well.

\section{Conclusions}

The presented model expresses the threshold shear velocity as a function of the near-surface moisture content, particle diameter, particle (or bulk) density, and fluid density. It is indexed to the moisture content at $-1.5 \mathrm{MPa}$, a unique value for a given soil. Furthermore, it contains only three model coefficients. Although the parameterisation was derived from theoretical considerations it is rather simple. Calibration and validation of the parameterisation on dry and wet sediment showed that it performs very well.

The soil aggregates that were used in our experiments were treated as individual particles with a density equal to their bulk density. The good agreement between observed and predicted threshold shear velocities means that when predicting mass transport of particles above a given soil, minimallydispersed particle-size distributions should be considered rather than the granulometric composition of the soil.

Finally, it can be concluded that the wind should dry the surface layer to moisture contents slightly lower than moisture conditions at $-1.5 \mathrm{MPa}$ before wind erosion will occur. Once this value is reached, a dramatic decrease in threshold shear velocity can be observed. However, sediment does not dry out uniformly and 'drier' and 'wetter' spots can be observed at the sediment surface. This means that mass transport of sediment can occur above a surface with a relatively high average moisture content.

\section{References}

Adamson, A.W., Gast, A.P., 1997. Physical chemistry of surfaces, $6^{\text {th }}$ edition. John Wiley \& Sons, New York.

Bisal, F., Hsieh, J., 1966. Influence of moisture on erodibility of soil by wind. Soil Sci. 102, 143-146.

Campbell, G.S., Schiozawa S., 1992. Prediction of hydraulic properties of soils using particle size distribution and bulk density data. In: International workshop on indirect methods for estimating the hydraulic properties of unsatured soils. Univ. Calif. Press, Berkeley.

Chepil, W.S., 1956. Influence of moisture on erodibility of soil by wind. Soil Sci. Soc. Am. Proc. 20, 288-292.
Cornelis, W.M., 2002. Erosion processes of dry and wet sediment as induced by wind and wind-driven rain: a wind-tunnel study. Ph.D. dissertation, Ghent University, Ghent.

Cornelis, W.M., Gabriels, D., 2003a. The effect of surface moisture on the entrainment of dune sand by wind: an evaluation of selected models. Sedimentology. In press.

Cornelis, W.M., Gabriels, D., 2003b. A simple model for the prediction of the deflation threshold shear velocity of loose particles. Sedimentology. In press.

Cornelis, W.M., Gabriels, D., Hartmann, R., 2003a. A conceptual model for the prediction of the threshold shear velocity for deflation of wet sediment. 1. Theory. Soil Sci. Soc. Am. J.. Accepted.

Cornelis, W.M., Oltenfreiter, G., Gabriels, D., Hartmann, R., 2003b. Splash-saltation of sand due to wind-driven rain: vertical deposition flux and sediment transport rate. Soil Sci. Soc. Am. J.. In press.

Cornelis, W.M., Oltenfreiter, G., Gabriels, D., Hartmann, R., 2003c. Splash-saltation of sand due to wind-driven rain: Horizontal flux and sediment transport rate. Soil Sci. Soc. Am. J.. In press.

de Lima, J.LM.P., van Dijk, P.M., Spaan, W.P., 1992. Splash-saltation transport under wind-driven rain. Soil Tech. 5, 151-166.

Erpul G., Norton, D. L., Gabriels D., 2002. Raindropinduced and wind-driven soil particle transport. Catena 47, 227-243.

Erpul G., Norton, D. L., Gabriels D., 2003. The effect of wind on raindrop impact and rainsplash detachment. Trans. ASAE. Accepted.

Fécan, F., Marticorena, B., Bergametti, G., 1999. Parametrization of the increase of the aeolian erosion threshold wind friction velocity due to soil moisture for arid and semi-arid areas. Ann. Geophysicae 17, 149157.

Fisher, R.A., 1926. On the capillary forces in an ideal soil: correction of the formulae given by W.B. Haines. J. Agric. Sci. 16, 492-503.

Gabriels D., Cornelis, W.M., Pollet, I., Van Coillie, T., Ouessar, M., 1997. The I.C.E. wind tunnel for wind and water erosion studies. Soil Tech. 10, 1-8.

Greeley, R., Iversen, J.D., 1985. Wind as a geological process on Earth, Mars, Venus and Titan. Cambridge Univ. Press, Cambridge.

Gregory, J.M., Darwish, M.M., 1990. Threshold friction velocity prediction considering water content. Pap. No. 902562 ASAE.

Hamaker, H.C., 1937. The London-van der Waals attraction between spherical particles. Physica 4, 10581072.

Harnby, N., 1992. The mixing of cohesive powders. In: Harnby, N., Edwards, M.F., Nienow, A.W. (Eds.), Mixing in the process industries, $2^{\text {nd }}$ edition. Nienow, Butterworth-Heinemann Ltd, Oxford, pp. 79-98.

Iversen, J.D., White, B.R., 1982. Saltation treshold on Earth, Mars and Venus. Sedimentology 29, 111-119.

Iversen, J.D., Greeley, R., Pollack, J.B., 1976a. Wind blown dust on Earth, Mars and Venus. J. Atmos. Sci., 33 2425-2429. 
Iversen, J.D., Pollack, J.B., Greeley, R., White, B.R., 1976b. Saltation threshold on Mars: the effect of interparticle force surface roughness, and low atmospheric density. Icarus 29, 381-393.

Logie, M., 1982. Influence of roughness elements and soil moisture on the resistance of sand to wind erosion. Catena, Suppl. 1, 161-174.

McKenna-Neuman, C., Nickling, W.G., 1989. A theoretical and wind tunnel investigation of the effect of capillary water on the entrainment of sediment by wind. Can. J. Soil Sci. 69, 79-96.

Namikas, S.L., Sherman, D.J., 1995. A review of the effects of surface moisture content on aeolian sand transport. In: Tchakerian V.P. (Ed.), Desert Aeolian Processes. Ed.. Chapman \& Hall, London. pp. 269-293.

Ritsema, C.J., Dekker, L.W., 1994. Soil moisture and dry bulk density patterns in bare sands. J. Hydrol., 154, 107131.

Ross, P.J., Williams, J., Bristow, K.L., 1991. Equation for extending water-retention curves to dryness. Soil Sci. Soc. Am. J. 55, 923-927.

Saleh, A., Fryrear, D.W., 1995. Threshold wind velocities of wet soils as affected by wind blown sand. Soil Sci. 160, 304-309.

Schofield, R.K., 1935. The $\mathrm{pF}$ of the water in soil. Trans. Int. Congr. Soil Sci. $3^{\text {rd }}$, II. 38-48.
Sarre, R.D., 1988. Evaluation of aeolian sand transport equations using intertidal zone measurements, Saunton Sands, England. Sedimentology 35, 671-679.

Shao, Y., 2000. Physics and modelling of wind erosion. Atmospheric and oceanographic sciences library, 23, Kluwer Academic Publishers, Dordrecht.

Shao, Y., Raupach, M.R., Leys, J.F., 1996. A model for predicting aeolian sand drift and dust entrainment on scales from paddock to region. Aust. J. Soil Res. 34, 309-342.

Sherman, D.J., Jackson D.W.T., Namikas S.L., Wang J.K., 1998. Wind-blown sand on beaches: an evaluation of models. Geomorphology 22, 113-133.

Spaan, W.P., van den Abeele, G.D., 1991. Wind borne particle measurements with acoustic sensors, Soil Tech. 4, 51-63.

Stout, J.E., Zobeck, T.M., 1996. Establishing the threshold condition for soil movement in wind-eroding fields. Proc. Int. Conf. on air pollution from agricultutal operations, MidWest Plan Service, Kansas City. pp. 65-71.

Stout, J.E., Zobeck, T.M., 1997. Intermittent saltation. Sedimentology 44, 959-970.

van Dijk, P.M., Stroosnijder, L., de Lima, J.L.M.P., 1996. The influence of rainfall on transport of beach sand by wind. Earth Surf. Proc. Landf. 21, 341-352. 